DOI: https://doi.org/10.11144/Javeriana.upsy18-3.qerc

\title{
¿Qué es un editor de una revista científica en América Latina?
}

\author{
WiLSON LÓPEZ-LóPEZ \\ Pontificia Universidad Javeriana, Colombia \\ ORCID: http://orcid.org/0000-0002-2964-0402
}

Para citar esta editorial: López-López, W. (2019). ¿Qué es un editor de una revista científica en América Latina? [Editorial]. Universitas Psychologica, 18(3), 1-4. https://doi.org/10.11144/Javeriana.upsy18-3.qerc
La tarea de editor ha comprometido mi vida entera. En este editorial, intentaré mostrar, a partir de una larga experiencia, lo que es ser un editor en Colombia y en la región.

A mis 12 o 13 años, edité mi primer boletín en el barrio donde vivía; la publicación pertenecía a una asociación de jóvenes que no prosperó, pero aún conservo algún impreso de esos que se imprimían en stencil (un papel azul que servía para multicopiar). Luego, a mis 16 o 17 años, hice parte de una revista que buscaba organizar información de muchos diarios del mundo; DATO, así se llamaba, fue un esfuerzo por sistematizar las noticias internacionales. Con el tiempo, esta revista murió; realmente era un adelanto para su época, pero eso no la salvó del naufragio.

Las innumerables lecturas solitarias y soliloquios en la universidad que me absorbieron durante, por lo menos, tres años, sobre la filosofía de la ciencia, culminaron con la publicación, en el año 1989, de mi primer artículo titulado "El concepto de progreso en la filosofía contemporánea" (LópezLópez, 1989), el cual marcó para siempre mi sustentación conceptual y el sentido de mi compromiso con la comprensión de las dinámicas de la comunicación científica. Además, dio vida a mi carrera como editor desde una línea de investigación que no se ha detenido a través de los años: la de mapear con herramientas cienciométricas y bibliométricas la producción científica en Iberoamérica.

En 1990, entre el final de mi pregrado y mi inicio como profesor universitario, asumí la edición del boletín de la Asociación Latinoamericana de Análisis y Modificación del Comportamiento (ALAMOC). Cada vez que salía un número era un logro y luego su distribución era el final de la tarea. En ese momento, empecé a descubrir que los procesos de edición estaban necesariamente atados a la construcción de comunidades que vinculaban la región y pasaban por la internacionalización. El boletín en papel terminaría por desaparecer, y daría lugar en el año 1999, 
gracias a parte de la comunidad construida entorno a él, a una nueva organización: el capítulo afiliado a la Association for Behavior Analysis International o ABAI y ABA Colombia, la cual se desarrolló como una plataforma de comunicación a través de internet. En la web de ABA Colombia, hicimos muchos boletines que desbordaron mis expectativas, creció exponencialmente en tres aspectos: en primer lugar, en la cantidad de contenidos como un proyecto de colaboración voluntaria de inteligencia colectiva; segundo, en el número de personas y en las exigencias de estas nuevas audiencias que accedían a los contenidos (en poco tiempo pasamos de un boletín de 500 ejemplares en papel a varios boletines con miles de visitantes) y, en tercer lugar, esta se convirtió en un escenario de formación, de diálogo y de relaciones. Todos ellos elementos centrales en la tarea de un editor (Consoli, Flores, \& Sharma, 2018).

Posteriormente, participe en la edición de un libro con un conjunto de pupilos -hoy ya profesores-, el Manual de análisis experimental del comportamiento. Evidentemente, la edición de un libro fue algo completamente distinto a la de una revista; estas son un libro que nunca termina, un libro sin fin, un libro infinito.

En esta misma época (1995) asumí la edición de mi primera revista, Suma Psicológica, que ya existía en la Fundación Universitaria Konrad Lorenz. Me propuse darle una perspectiva internacional y lo conseguí: conformé un comité internacional, amplié la convocatoria para incluir autores por fuera de la institución en el contexto nacional e internacional, sometí la revista a PsycINFO, base de datos de la American Psychological Association (APA), y fue aceptada. Entendía en ese momento que las revistas deben ser menos endogámicas y buscar estándares internacionales.

Como editor, organicé en el marco del II Congreso Iberoamericano de Psicología en el año 1998 en Madrid, el Primer Simposio de Editores de Revistas de Psicología de Iberoamérica que dio lugar subsiguientemente a la Red Iberoamericana de Editores de Revistas de Psicología, la cual se encuentra en los Congresos
Iberoamericanos de Psicología organizados por la Federación Iberoamericana de Asociaciones de Psicología (FIAP), entidad que fundé junto a colegas unos años después. Luego, participé en encuentros de Congresos Interamericanos de Psicología y, en Colombia, conformamos la Red de Editores con ocasión del encuentro bianual de nodos de investigación, organizados por la Asociación Colombiana de Facultades de Psicología (Ascofapsi). Estos escenarios de intercambio eran necesarios, pues de la cualificación de los editores dependería el ingreso de revistas a los sistemas de indexación y a su visibilidad. Una sola revista no podría ser visible, ni podría darle visibilidad a la creciente producción de la región. Latinoamérica es la zona del mundo con más programas de formación, más estudiantes y más psicólogos, y es el escenario natural de usos del conocimiento que producimos, por tanto, en este sentido, la estrategia era y sigue siendo la cooperación más que la competencia, y es bajo esta perspectiva, que luego fui invitado a eventos de editores en Chile, México y Brasil.

En el año 2002, emprendí varias empresas editoriales; entre las más importantes, la fundación de Universitas Psychologica en la Pontificia Universidad Javeriana - editar la revista fue mi carta para que el decano de la época me nombrara profesor de planta en la universidad-. Universitas Psychologica es hoy referente en el contexto iberoamericano, en ella he buscado plasmar todas mis ideas para lo cual conté con el apoyo de diferentes instancias de la Universidad. En esa misma época, en el aeropuerto de Bogotá junto con un profesor español, creé el International Journal of Clinical and Health Psychology, del que inicialmente fui editor asociado y del que luego tuve que desprenderme (sin mi consentimiento y en forma muy desafortunada).

En ese periodo, edité algunos números especiales de la Revista Latinoamericana de Psicología, y para los primeros años del nuevo milenio, el director general de Redalyc, mi hoy en día amigo entrañable Eduardo Aguado López, me contactó para acompañar el proceso de desarrollo de esa red. En la actualidad, puedo decir que Universitas Psychologica, Redalyc y el 
portal de psicología FIAP-Redalyc (único portal de acceso abierto de revistas de psicología) han comprometido una parte importante de mis sueños y de mi realización como investigador y psicólogo, porque construyéndolos he aprendido y consolidado el oficio de editor científico.

Debo mencionar que en ese periodo fui elegido miembro de la comisión Scielo Colombia y de otras, que intentaron hacer un aporte al mejoramiento del sistema de evaluación de revistas del sistema colombiano de ciencia y tecnología Publindex (desafortunadamente sin lograrlo), y no puedo dejar de reconocer lo mucho que aprendí con Félix de Moya y el grupo Scimago.

En este camino, he podido aprender, compartir y construir con otros editores, con autores, con filósofos y con sociólogos de la ciencia, cienciómetras y bibliómetras, el sentido de la comunicación en la ciencia, sus constantes transformaciones $\mathrm{y}$, por supuesto, los retos permanentes que comprometen la labor del editor de una revista científica, en especial, en Colombia y en América Latina, y las diferencias que supone con los editores de países con más recursos (Aguillo Caño, Uribe-Tirado, \& LópezLópez, 2017).

Un editor en Colombia y América Latina tiene que, además de atender las funciones clásicas de su cargo, participar en el desarrollo de una política editorial de la revista y ocuparse de su calidad editorial y científica, de su visibilidad, difusión, formación, gestión administrativa y de las políticas. Estos procesos suelen requerir competencias que desbordan las exigencias normales de un académico tradicional, donde las funciones de docencia, investigación y proyección social están cada vez más delimitadas en términos de competencias y de tiempos, y no como las del editor de una revista científica (López-López et al., 2018).

A lo largo de estos años, he buscado, en este espacio editorial, contribuir a la transferencia de parte de mi experiencia y conocimientos como editor, con los procesos de formación a través de los coordinadores editoriales de la revista, por ejemplo (López-López, 2008; 2009a; 2009b; 2010; 2015; 2017; 2018a; 2018b; 2018c; 2018d).
Universitas Psychologica ha sido un modelo y ha buscado estar siempre a la vanguardia en todos los procesos; ha tenido crisis de éxito, crisis que nos han permitido aprender; no siempre hemos podido responder a la velocidad que quisiéramos. Es frecuente que olvidemos que la revista es aún joven, 17 años, y que este proyecto colectivo ha podido crecer gracias al soporte de la Facultad, la Editorial, la vicerrectoría académica y en definitiva de la Universidad que se ha comprometido y apostado por el desarrollo de las revistas, y gracias también al apoyo de las comunidades académicas nacionales, regionales e internacionales.

A partir de la condición de estos libros infinitos, seguramente sus editores tendremos que reinventarnos y transformarnos una y otra vez.

\section{Referencias}

Aguillo Caño, I. F., Uribe Tirado, A., \& López-López, W. (2017). Visibilidad de los investigadores colombianos según sus indicadores en Google Scholar y ResearchGate. Diferencias y similitudes con la clasificación oficial del sistema nacional de ciencia - COLCIENCIAS. Revista Interamericana de Bibliotecología, 40(3), 221-230. https://doi.org/10.17533//u dea.rib.v40n3a03

Consoli, A. J., Flores, I., \& Sharma, H. (2018). Psychology in Latin America: Legacies and Contributions. International Psychology Bulettin, 22 (2), 29-37. Retrieved from https://www.div52.net/images/PDF/D 52-IPB/IPB-2018-22-2-spring.pdf

López-López, W. (1989). El concepto de progreso en la filosofía de la ciencia contemporánea. BoletínADFP, September, 13-18. Retrieved from https://www.academia.edu/316410/el _concepto_de_progreso_en_la_filosofia_d e_la_ciencia

López-López, W. (2008). Editorial. Universitas Psychologica, 7(3), 621-622. Retrieved 
from https://revistas.javeriana.edu.co/inde x.php/revPsycho//issue/view/23

López-López, W. (2009a). Scientometrics and Intellectual Production Assessment, Universitas Psychologica, 8(2), 291-292. Retrieved from https://revistas.javeriana.ed u.co/index.php/revPsycho/article/view/488

López-López, W. (2009b). Scientific Communication Perspectives in the New Digital Realities. Universitas Psychologica, 8(3), 575-578. Retrieved from https://revistas.javeriana.edu.co/inde x.php/revPsycho//issue/view/32

López-López, W. (2010). Knowledge management and networks: the new Iberoamerican Psychology Journal Editors Network. Universitas Psychologica, 9(3), 607-609. Retrieved from https://revistas.javeriana.edu.co/inde x.php/revPsycho//issue/view/42

López-López, W. (2015). Interdisciplinariety: A perspective from the dynamics of scientific production and communication. Universitas Psychologica, 14(1), 1-2. Retrieved from https://revistas.javeriana.ed u.co/index.php/revPsycho/article/view/129 06

López-López, W. (2017). ¿Puede la cienciometría contribuir a la evaluación de la producción intelectual? Universitas Psychologica, 16(4), 1-3. https://revistas.javeriana.edu.co/index. $\mathrm{php} / \mathrm{revPsycho/article/view/20814}$

López-López, W. (2018a). Las dinámicas del conocimiento: su aporte a un mundo con más equidad. Universitas Psychologica, 17(2), 1-2. Retrieved from https://revistas.javeriana.edu.co/inde x.php/revPsycho/article/view/21898

López-López, W. (2018b). Las revistas de psicología en Iberoamérica: historia, estado y perspectivas. Universitas Psychologica, 17(3), 1-3. Retrieved from https://revistas.javeriana.edu.co/inde x.php/revPsycho/article/view/22424

López-López, W. (2018c). Sobre la evaluación de la investigación y los investigadores: Criticas a las métricas y recomendaciones.
Universitas Psychologica 17(4), 1-2. https://d oi.org/10.11144/Javeriana.upsy17-4.seii

López-López, W. (2018d). Un cambio en la concepción de la edición académica. Del conocimiento centrado en los productos al conocimiento orientado a los servicios. Universitas Psychologica, 17(1), 1-2. https://revistas.javeriana.edu.co/index. php/revPsycho/article/view/21536

López-López, W., Caycedo, C., Acevedo Triana, C., Hurtado-Parrado, C., Silva, L., \& Aguilar-Bustamante, M. C. (2018). Training, academic and professional development in psychology in Colombia: Challenges and perspectives. In G. Rich, A. Padilla-López, L. K. De Souza, L. Zinkiewicz, J. Taylor \& J. L. Binti Jaafar (Eds.), Teaching psychology around the world (Vol. 4, pp. 53-79). Newcastle-upon-Tyne, UK: Cambridge Scholars Publishing. 